\title{
Moisture Solubility for Differently Conditioned Transformer Oils
}

\author{
Y. Du ${ }^{1}$, A. V. Mamishev'2 , B. C. Lesieutre, M. Zahn and S. H. Kang ${ }^{3}$ \\ Massachusetts Institute of Technology \\ Department of Electrical Engineering and Computer Science \\ Laboratory for Electromagnetic and Electronic Systems \\ Cambridge, MA, USA
}

\begin{abstract}
It is important to monitor the moisture content of transformer oil in a transformer. One parameter of particular interest is the moisture solubility of transformer oil. It has been reported that transformer oils under different conditions have different solubility. Measurements of solubility for four different types of conditioned oil are presented in this paper: fresh Shell Diala AX oil, lab-aged Shell Diala A oil, Texas Utility used transformer oil, and Ramapo Substation used transformer oil. To avoid the difficulty of achieving full saturation, this paper proposes an alternative method of measuring the moisture solubility in transformer oil using a relative humidity sensor. It utilizes the linearity between the relative humidity of the oil and the moisture content of the oil, to measure the solubility indirectly. The measured results of fresh oil, lab-aged oil, and the Texas Utility oil are very close, and only Ramapo oil shows different sensor response characteristics and solubility.
\end{abstract}

\section{INTRODUCTION}

$\mathrm{M}$ OST transformers in electric power delivery systems around the world are filled with a dielectric liquid. The liquid functions both as electrical insulation and as a heat transfer agent. Newer liquids such as silicone and esters have their applications in special-purpose transformers, and with more environmental concerns, there are new alternatives such as edible seed-oil-based fluid [1]. However, the liquid in the majority of transformers is petroleum-based insulating mineral oil. Conventional transformer oil is made 'by refining a fraction of the hydrocarbons collected during the distillation of a petroleum crude stock' [2].

It is well recognized that moisture in oil has detrimental effects on transformer performance. The presence of moisture in transformers deteriorates transformer insulation by decreasing both the electrical and mechanical strength. The importance of moisture presence in paper and oil systems has been recognized since the 1920 's. Knowing moisture in oil can also predict the steady state moisture content in transformer board in equilibrium with the oil [3].

One important parameter in oil moisture measurements is the water solubility. When the moisture in oil exceeds the solubility for that temperature, free water will form. The conventional way to measure water solubility is to make a saturated oil sample and then test the absolute moisture content. To achieve full saturation in transformer oil is difficult, especially at high temperature because of the high solubility. This paper proposes an alternative method of measuring the solubility using a relative humidity sensor.
There is a general perception that oil under different aging conditions has different solubility. It is important to know the level of accuracy of this general claim, which in turn determines if extra precautions are necessary. Testing was carried out for four differently conditioned oils.

\section{TRANSFORMER OIL AND ITS MOISTURE MEASUREMENTS}

An excellent review of the basic concepts that are used in this paper is given in [4]. A brief introduction is given here. Transformer oil is made by refining crude oil. It is mainly a mixture of hydrocarbon compounds of three classes: alkanes, naphthenes, and aromatic hydrocarbons. These molecules have little or no polarity. A minor part of the constituents is that of polar and ionic species, which may greatly influence the chemical and electrical properties of the oil. Polar compounds found in transformer oil usually contain oxygen, nitrogen, or sulfur. Ionic compounds would typically be organic salts found only in trace quantities' [4].

\subsection{WATER IN OIL}

Insulating oils, such as transformer oil, have a low affinity for water. However, the solubility increases markedly with temperature for normally refined naphthenic transformer oil. This will be discussed more quantitatively later in this paper. Water can exist in transformer oil in three states:

1. in practical cases, most water in oil is found in the dissolved state; 
2. certain discrepancies in examining the moisture content using different measurement techriques suggests that water also exists in the oil tightly bound to oil molecules, especially in deteriorated oil; and

3. when moisture in oil exceeds the saturation value, there will be free water precipitated from oil in suspension or drops. Moisture in oil is measured in parts per million (ppm) using the weight of moisture divided by the weight of oil $(\mu \mathrm{g} / \mathrm{g})$.

\subsection{RELATIVE HUMIDITY}

Relative humidity (RH) can be defined in terms of the moisture mixing ratio $r$ versus the saturation mixing ratio $r_{s}, \mathrm{RH} \%=100 r / r_{s}$, which is a dimensionless percentage. Relative humidity for air is the water vapor content of the air relative to its content at saturation. Relative humidity for oil is the dissolved water content of the oil relative to the maximum capacity of moisture that the oil can hold at that temperature. Because the saturation mixing ratio is a function of pressure, and especially of temperature, the relative humidity is a combined index of the environment and reflects more than water content [5].

\subsection{MOISTURE MEASUREMENT METHODS FOR TRANSFORMER OIL}

There are two types of off-line methods to measure the moisture in oil: the Karl Fischer reaction method and the pressure gauge method.

The standard test method for measuring water in transformer oil is the ASTM D 1533 test [6] known as the Karl Fischer reaction test. It is based on the reaction of halogens with water in the presence of anhydrous sulfur dioxide. It is widely used because of its high selectivity and sensitivity. There are commercial instruments such as the Mitsubishi Moisture Meter to accomplish the Karl Fischer titration automatically. With these instruments, an oil sample can be directly injected into the reaction unit and the moisture content will be given at the end of the reaction. In the case that the liquid samples contain interfering substances reacting with the reagents, the oil samples are placed in a water vaporizer and then the water vapor is circulated to the reaction unit to be measured.

The pressure gauge method 'consists of degassing and dehydrating, by extraction in a vacuum, a known quantity from the studied body, oil, paper impregnated or non-impregnated, then to separate the different volatile compounds collected either by condensation on a cold point, or by combustion' [7]. The extracted water is then heated to vapor and the vapor pressure, measured by a mercury pressure gauge, is proportional to the quantity of water content. This method was proposed by B. Fallou [7], but not widely used.

These direct methods require removing the moisture, so they are not practical for on-line monitoring of the transformer insulation.

There are commercially available meters that measure the relative humidity of the transformer oil in real time such as the Harley moisture sensor from J. W. Harley Inc., and Aquaoil 100A from Syprotech. The relative humidity can be converted to absolute moisture content by multiplying the relative hurnidity with the saturation moisture (solubility) of transformer oil at the measured temperature.
Table 1. Comparison of estimated parameters for the Arrhenius form in (1) of the solubility of water in transformer oil as a function of temperature.

\begin{tabular}{|l|c|c|c|}
\hline \hline & Oommen [19] & Griffin [9] & Shell [14] \\
\hline $\mathrm{A}$ & 7.42 & 7.09 & 7.3 \\
$\mathrm{~B}$ & 1670 & 1567 & 1.630 \\
\hline
\end{tabular}

\section{WATER SOLUBILITY IN OIL}

\subsection{EXISTING METHODS}

One way of determining water solubility is by the use of the new ASTM Standard Test Method D 4056-92 [8]. This method estimates the solubility of water in hydrocarbons at different temperatures based on calculations from values for density, refractive index, and molecular weight. This is not a very practical way to measure the water solubility. A more conventional way is to make a saturated oil sample and then measure the absolute moisture content using the standard test method for measuring water in transformer oil, the ASTM D 1533 test method known as the Karl Fischer reaction method [6]. To achieve full saturation in transformer oil is not a trivial task, especially at high temperature because of the increasing solubility.

Two ways have been generally adopted for making saturated solutions:

1. Bubble moist air through the oil. We found it difficult to achieve saturation at high temperature using this method without a well designed system like that shown in the Appendix of [9].

2. Directly add free water.

One improper practice is simply adding an excess amount of water to a sample, shake it up, let stand overnight and then measure water concentration. It is not an acceptable way of measuring the solubility because the diffusion process in the oil is very slow, and letting the solution stand overnight does not guarantee full dissolution. Also, excess free water in the oil will cause an erroneous measurement of water solubility, i.e. the free water might be sampled and measured as water dissolved in oil. Even though water is heavier than the oil, small water bubbles can still exist near the upper body of the oil by surface tension. The measurement results of such samples are non-repeatable and inconsistent. The proper implementation of this method is to add water and mix well until free water is observed. The mixture should be centrifuged to remove any entrained water and then decanted. The correct implementation of both methods requires extra equipment and care.

\subsection{LITERATURE REPORTED WATER SOLUBILITY IN OIL}

The water solubility for oil can be expressed in Arrhenius form as

$$
\log r_{s}=A-\frac{B}{T}
$$

where $r_{s}$ is the saturation solubility of water in oil in ppm and $T$ is the temperature in ${ }^{\circ}$ Kelvin. Different coefficients $A$ and $B$ by different authors are shown in Table 1 , and the calculated oil solubility at different temperatures is given in Table 2.

The Shell and Oommen's data agree very well over the entire temperature range. Griffin's data differs from the Shell and Oommen data 
Table 2. Water saturation solubility in oil in ppm for different temperatures by different investigators calculated using Table 1 values in (1).

\begin{tabular}{|r|r|r|r|}
\hline \hline$T\left({ }^{\circ} \mathrm{C}\right)$ & Oommen & Griffin & Shell \\
\hline 0 & 20 & 23 & 22 \\
10 & 33 & 36 & 35 \\
20 & 53 & 56 & 55 \\
30 & 82 & 83 & 84 \\
40 & 122 & 122 & 124 \\
50 & 179 & 174 & 180 \\
60 & 255 & 243 & 255 \\
70 & 358 & 334 & 355 \\
80 & 491 & 450 & 484 \\
90 & 663 & 596 & 648 \\
100 & 880 & 777 & 855 \\
\hline
\end{tabular}

at high temperatures, perhaps due to difficulty of achieving saturation at high temperature with moist bubbles.

\section{PROPOSED METHOD}

To avoid the error caused by taking the moisture value of a nonsaturated solution as solubility, or solution with excessive free water, an alternative easily implemented method is proposed for measuring moisture solubility in transformer oil. The linearity between the relative humidity of the oil and the moisture content of the oil is utilized to find the solubility:

$$
r=r_{s} \times \frac{R}{100}
$$

where $R$ is the relative humidity $(\%), r$ the water concentration in ppm at temperature $T$, and $r_{s}$ is the water solubility in ppm at the same temperature $T$. By measuring the slope of the curve of moisture concentration $v$ s. relative humidity, or the intercept of the curve at $R=100 \%$, one can find the water solubility instead of trying to directly measure the moisture content at $100 \%$ relative humidity.

The Mitsubishi moisture meter model CA-05, based on microprocessor controlled Coulometric Karl Fischer titrimetry, is used to measure the absolute moisture content in oil. The commercially available Harley moisture sensor, a capacitive polymer sensor $[10,11]$, is used to measure the relative humidity of transformer oil. To verify that the Harley moisture sensor responds to the relative moisture level rather than the absolute moisture level, previous research [12] used two identical Harley sensors at various temperatures in both transformer oil and silicone oil which have different saturation moisture levels. An experiment that had the same absolute moisture level in transformer oil and silicone oil at the same temperature had different output voltages. This confirmed that the Harley sensor does not respond to the absolute moisture content because if it did the output voltages of the two sensors in the different oils would be the same.

Figure 1 shows the Harley CT-880-S moisture sensor used in this investigation. It consists of a dual sensor [13], a full range ( 0 to $100 \%$ $\mathrm{RH})$ thin-film capacitive humidity sensor and a thin-film platinum RTD temperature sensor, combined with a linearized 4 to $20 \mathrm{~mA}$, two-wire current transmitter. The unit transmits a 4 to $20 \mathrm{~mA}$ current signal for a moisture range of 0 to $100 \%$ saturation. The temperature corrected current output is converted into equivalent dc voltage output across an externally connected load resistor. The newly shipped sensor was

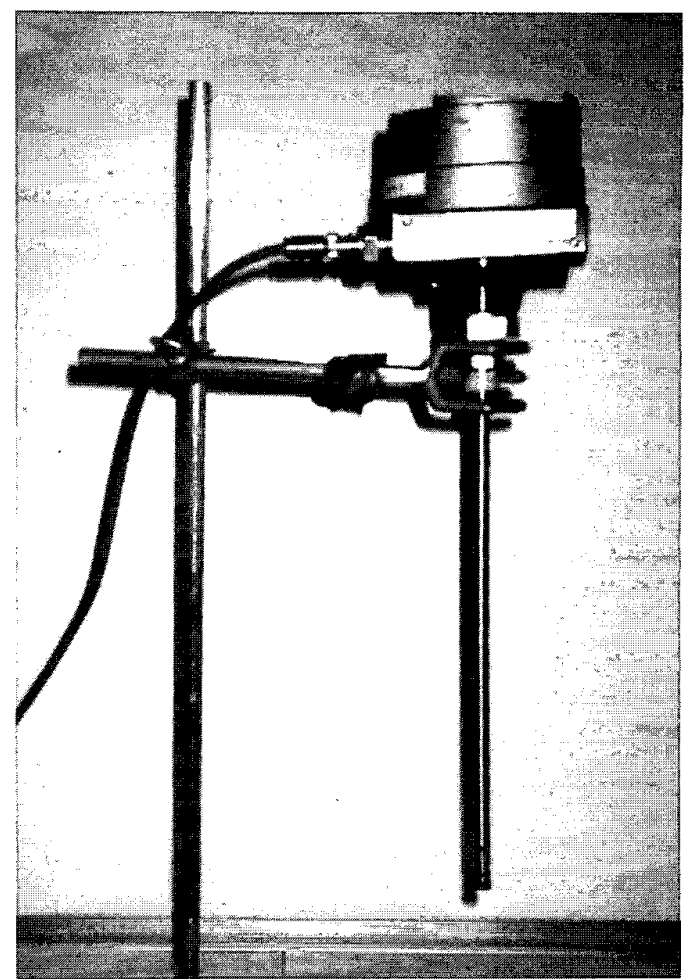

Figure 1. Harley CT-800 moisture sensor. The sensing element is at the bottom of the long rod.

calibrated in fresh Shell Diala AX oil as shown in Figure 2. The titration results are obtained by dividing the moisture content by the solubility of the Shell Diala AX oil at that temperature. The reported solubility value of Shell Diala AX oil [14] is used for calibration. The ideal relative humidity $R(\%)$ is obtained by converting the output voltage $V$ by the ideal transfer function

$$
R=\frac{\left(V-I_{\min } R\right)}{4} 100=25(V-1)
$$

where $I_{\min }=4 \times 10^{-3}$ A and $R=250 \Omega$. After two years of use in hot transformer oil in our laboratory apparatus, the sensor was recalibrated as shown in Figure 3. By calibration, the relative humidity of the oil is related to the measured sensor output voltage by

$$
R=22.005\left(V-V_{\min }\right)-1.308
$$

where $V_{\min }=1.06 \mathrm{~V}$ for the calibrated sensor. The fitted function of (4) differs from the ideal function given in (3) due to the instrumentation deviations and the drifting of operating point of the sensor over the years. Nevertheless, the calibration indicates a very good linear relationship between-sensor output and the relative humidity.

\section{DIFFERENTLY CONDITIONED OILS}

The measurements are taken for four types of differently conditioned oils at $35^{\circ} \mathrm{C}$ : fresh Shell Diala AX oil, lab-aged Shell Diala A oil, Texas Utility (TU) used transformer oil, and Ramapo Substation used transformer oil. The Shell Diala A oil is Type I oil which is intended 


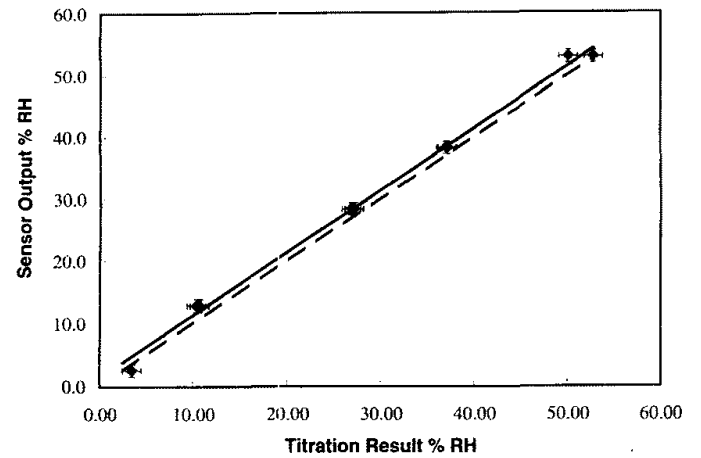

Figure 2. The subject relative humidity sensor calibrated in Shell Diala AX oil at $35^{\circ} \mathrm{C}$ when first arrived in 1995 (calibrated by D. E. Schlicker at MIT HV Research Lab.) The dashed line is the ideal output and the solid line is the linear regression of measured output.

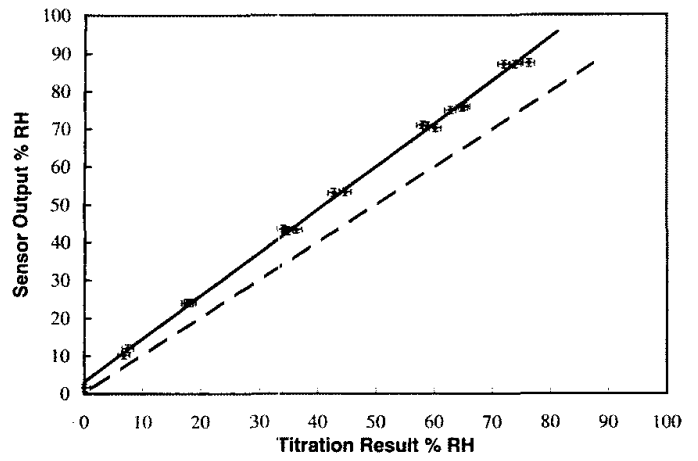

Figure 3. The relative humidity sensor calibrated in Shell Diala AX oil at $35^{\circ} \mathrm{C}$ in 1997 after two years in service. The dashed line is the ideal output and the solid line is the linear regression of the measured output.

for use where normal oxidation resistance is required. Shell Diala AX oil is Type II oil, for more severe service applications requiring greater oxidation resistance. It contains $\approx 0.2 \%$ wt ( $2000 \mathrm{ppm}$ ) of oxidation inhibitor. The lab-aged oil is prepared by heating new oil at $70^{\circ} \mathrm{C}$ for two weeks with a mixture of moisture and oxygen, because heat, moisture and oxygen are the major aging factors. The oil is circulated within an open vessel by a pump for thorough mixing. The TU oil was taken from a transformer that was in service at Texas Utilities. The Ramapo oil was taken from a single phase of a $500 / 345 \mathrm{kV}, 333$ MVA (per phase) transformer at the Ramapo Substation that experienced failure due to static electrification. Because of the small quantity of the oil availability, the tested Ramapo oil is a mixture of $80 \%$ Ramapo original oil and $20 \%$ of new Shell Diala A oil.

Three of the tested oils were analyzed by Doble Engineering Company. Representative results are listed in Table 3 [15]. The interfacial tension (IFT) and the neutralization number (mg KOH/g) of the oil provide an indication of the degree of aging and contamination. In general, the more aged the oil, the lower the IFT and the larger the neutralization number.
Table 3. Analysis of the subject oils performed by Doble Engineering a year before the solubility test [15].

\begin{tabular}{|l|c|c|c|}
\hline \hline & $\begin{array}{c}\text { Fresh shell } \\
\text { Diala A }\end{array}$ & $\begin{array}{c}\text { Texas } \\
\text { Utility }\end{array}$ & Ramapo \\
\hline Total PCB Content, ppm & $<2$ & $<2$ & $<2$ \\
Carbon Monoxide $(\mathrm{CO}), \mathrm{ppm}$ & 0 & 22 & 66 \\
Carbon Dioxide $\left(\mathrm{CO}_{2}\right), \mathrm{ppm}$ & 252 & 748 & 484 \\
Ethylene $\left(\mathrm{C}_{2} \mathrm{H}_{4}\right), \mathrm{ppm}$ & 0 & 11 & 6 \\
Water, ppm & 20 & 40 & 21 \\
Neutralization No. $\mathrm{mg} \mathrm{KOH} / \mathrm{g}$ & $<0.01$ & 0.01 & $<0.01$ \\
IFT, $10^{-5} \mathrm{~N} / \mathrm{cm}, 25 \mathrm{C}$ & 42 & 32 & 37 \\
\hline
\end{tabular}

Table 4. Additional analysis of the subject oils after solubility test and later received non-mixed Ramapo oil by Doble Engineering [20]. * erratic

\begin{tabular}{|l|l|c|c|c|c|}
\hline \hline $\begin{array}{c}\text { Screen } \\
\text { test }\end{array}$ & $\begin{array}{c}\text { ASTM } \\
\text { method }\end{array}$ & $\begin{array}{c}\text { Non-mixed } \\
\text { Ramapo }\end{array}$ & $\begin{array}{c}\text { Tested } \\
\text { Ramapo }\end{array}$ & $\begin{array}{c}\text { Tested } \\
\text { TU }\end{array}$ & $\begin{array}{c}\text { Fresh } \\
\text { shell [14] }\end{array}$ \\
\hline Color & D 1500 & $L 1.5$ & $L 1.5$ & $L 1.5$ & $<L 0.5$ \\
IFT, $10^{-5} \mathrm{~N} / \mathrm{cm}, 25 \circ$ & D 971 & 38 & 36 & 32 & 47 \\
Neutralization, $\mathrm{mg} \mathrm{KOH} / \mathrm{g}$ & D 974 & $<0.01$ & $<0.01$ & $<0.01$ & $<0.01$ \\
Power Factor, \% at 25 $2{ }^{\circ}$ & D 924 & $0.201^{*}$ & 0.025 & 0.024 & 0.02 \\
\hline \hline
\end{tabular}

Table 5. Differences in the IR scans shown in Figures 6 and $7{ }^{*}$ line, left dip lower than right dip; \# line, left dip higher than right dip.

\begin{tabular}{|c|c|c|}
\hline $\begin{array}{c}\text { Wave } \\
\text { number }\end{array}$ & $\begin{array}{c}\text { Figure 6 } \\
\text { Ramapo }\end{array}$ & $\begin{array}{c}\text { Figure 7 } \\
\text { TU }\end{array}$ \\
\hline 700 & 0.24 & 0.31 \\
$720 \rightarrow 750$ & $\sim 0.5^{*}$ & $\sim 0.6^{\#}$ \\
970 & $\mathbf{0 . 4 2}$ & 0.40 \\
\hline
\end{tabular}

Additional Doble tests were performed later for the tested Ramapo and TU oils and the later shipped non-mixed Ramapo oil. The results are summarized in Table 4. Although the color of Ramapo is darker than TU, they do not differ much in the color scale defined by ASTM standard D1500 [16]. In addition, there were no significant differences measured in the neutralization number for the tested oils.

infrared (IR) scans are also performed for the oils. The IR analysis is used by organic chemists for qualitative determination of the presence or absence of specific functional groups in a mixture [17]. One IR scan was done with a $1 \mathrm{~mm}$ cell path and with new oil in the path of the reference beam. This type of test for the tested Ramapo oil and TU oil is shown in Figures 4 and 5. This allows for detection of oxidation inhibitor at $3660 \mathrm{~cm}^{-1}$ and for carbonyl compounds at 1700 to $1730 \mathrm{~cm}^{-1}$. Little to none oxidation inhibitor was detected for all oils. Carbonyl compounds are mostly from oxidation of insulating materials. Both non-mixed Ramapo oil and tested mixed Ramapo oil have a little more absorbance in this region, suggesting that they contain a higher amount of (non-acid) carbonyl compounds than the other two oils.

Another IR scan was performed using a $0.2 \mathrm{~mm}$ cell path and air as the reference, which provides a fingerprint of the oil. Shown in Figures 6 and 7 are the test results for the tested Ramapo and TU oils. The differences are subtle, nevertheless are noticeable. The original test curves were recorded on large chart paper, more than twice the size shown here and the difference among curves were easier to be identified. Some differences are listed in Table 5 for example. The signature band is mostly $\sim 700$ to $1200 \mathrm{~cm}^{-1}$. It shows that the Ramapo and TU oils are different products. 


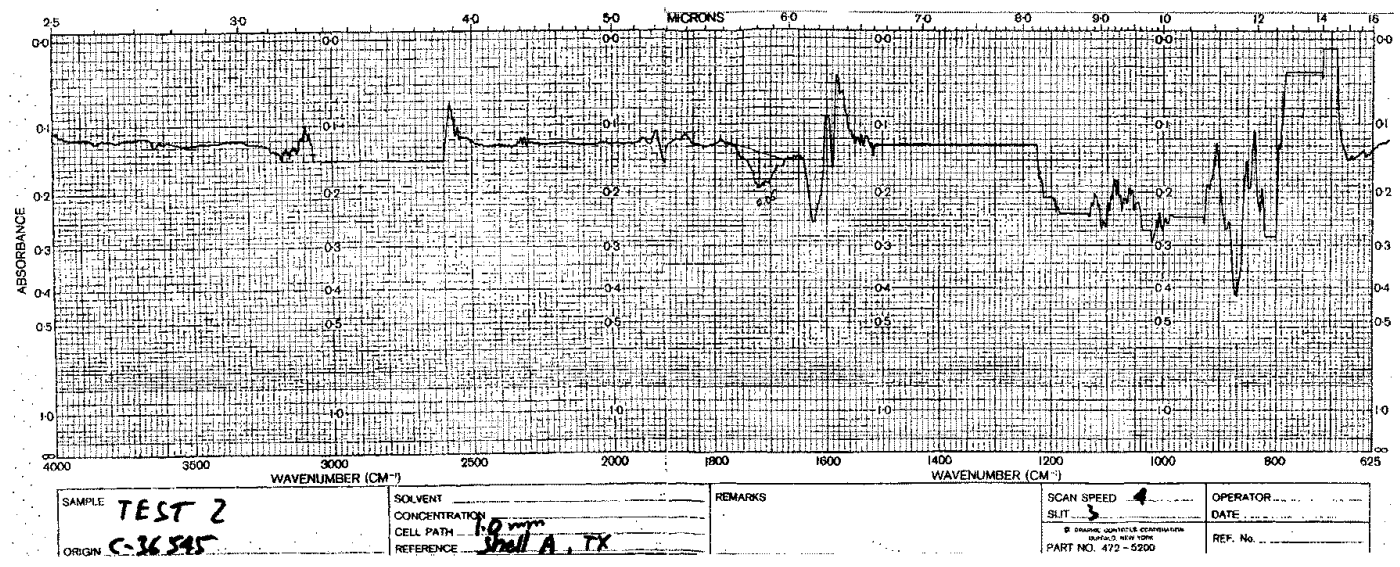

Figure 4. IR scan for the tested Ramapo oil with $1 \mathrm{~mm}$ cell path and new oil as reference beam. Little to none of oxidation inhibitor was detected at $3660 \mathrm{~cm}^{-1}$. Carbonyl compounds detection region at 1700 to $1730 \mathrm{~cm}^{-1}$ shows more absorbance than that of TU oil in Figure 5.

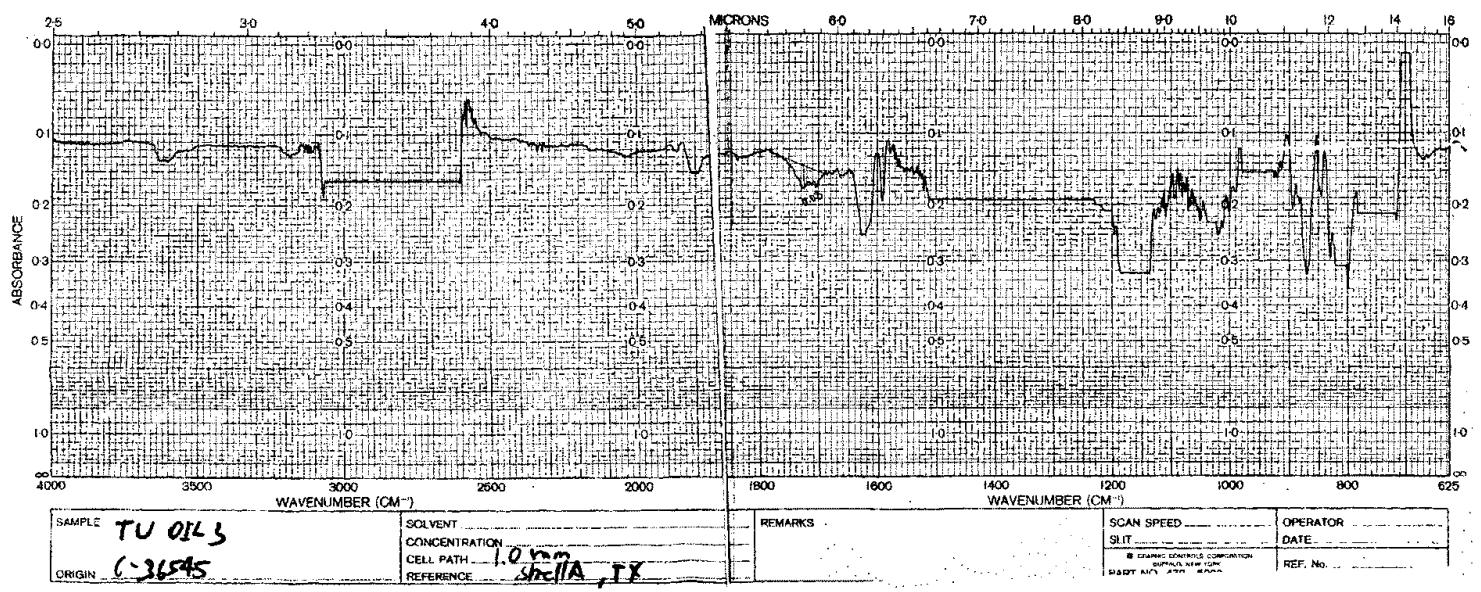

Figure 5. IR scan for the tested TU oil with $1 \mathrm{~mm}$ cell path and new oil as reference beam. Little to none oxidation inhibitor was detected at $3660 \mathrm{~cm}^{-1}$. Carbonyl compounds detection region at 1700 to $1730 \mathrm{~cm}^{-1}$ shows less absorbance than that of Ramapo oil in Figure 4.

\section{MEASUREMENT RESULTS}

The oil is contained in a $1000 \mathrm{ml}$ kettle. It is well mixed by a magnetic stirrer and the temperature is controlled by an Omega temperature probe and controller. The moisture is bubbled into the kettle by flowing a constant air flow through a flask of de-ionized water.

The measured oil solubilities and conductivities are listed in Table 6 and the data and fitted linear curves are shown in Figure 8. The conductivities of the oils are measured by a gapped tuning capacitor immersed in the oils. The moisture measurements for the Ramapo oil appeared to be erratic and a linear interpolation did not produce meaningful reading near the origin. The possible reasons are discussed in Section 6.1.

\subsection{DISCUSSION}

The results obtained with fresh oil, lab-aged oil, and the TU oil are very close, whereas the result for Ramapo oil is very different from the rest. Lab tests show the Ramapo oil is not very aged, however, an erratic power factor is measured. There might be contaminants or moist
Table 6. Comparison of measured water solubility at $35^{\circ} \mathrm{C}$ and conductivity in differently conditioned oils.

\begin{tabular}{|c|c|c|c|c|}
\hline \hline Oil type & Fresh shell & Aged shell & TU & Ramapo \\
\hline Solubility $(\mathrm{ppm}), 35^{\circ} \mathrm{C}$ & 102 & 104 & 108 & 142 \\
Conductivity $(\mathrm{pS} / \mathrm{m})$ & $0.7\left(35^{\circ} \mathrm{C}\right)$ & $7.2\left(70^{\circ} \mathrm{C}\right)$ & $9.5\left(35^{\circ} \mathrm{C}\right)$ & $10.1\left(35^{\circ} \mathrm{C}\right)$ \\
\hline \hline
\end{tabular}

particles in the Ramapo oil that cause the observed moisture sensor response. Indeed Golovan et al. [18] also observed that the increase of polar impurities in the oil "leads to a significant increase in oil hygroscopicity and a breakdown of the linear relationship between the water uptake capacity and the relative humidity of the air". This observation also serves as a caution for using the moisture sensor in contaminated oil. Because of the nonlinear behavior of the sensor output, the predicted value of solubility of Ramapo oil is only a rough estimation.

The proposed method is effective only when the sensor response is linear. Another possibility is that the contaminants in the oil could affect the chemical reaction process of the Karl Fischer titration and 


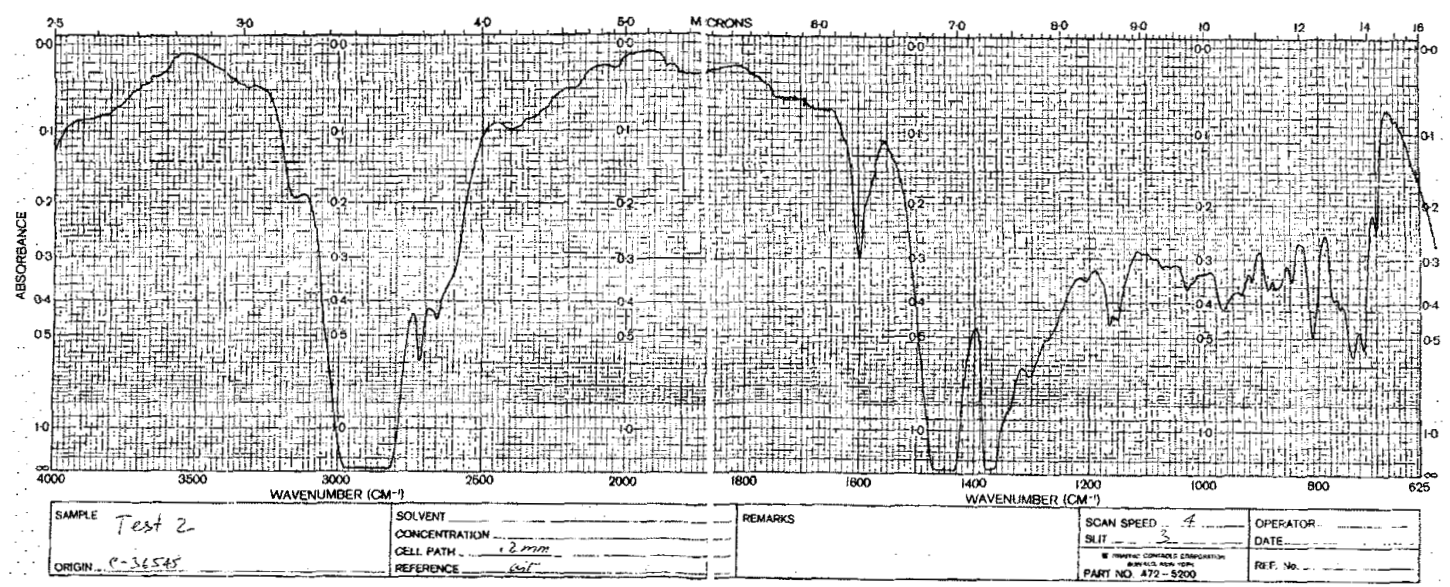

Figure 6. IR scan for the tested Ramapo oil with $0.2 \mathrm{~mm}$ cell path and air as reference beam. The absorbance difference in signature band $\sim 700$ to $1200 \mathrm{~cm}^{-1}$ shows that the Ramapo and TU oils are different products.

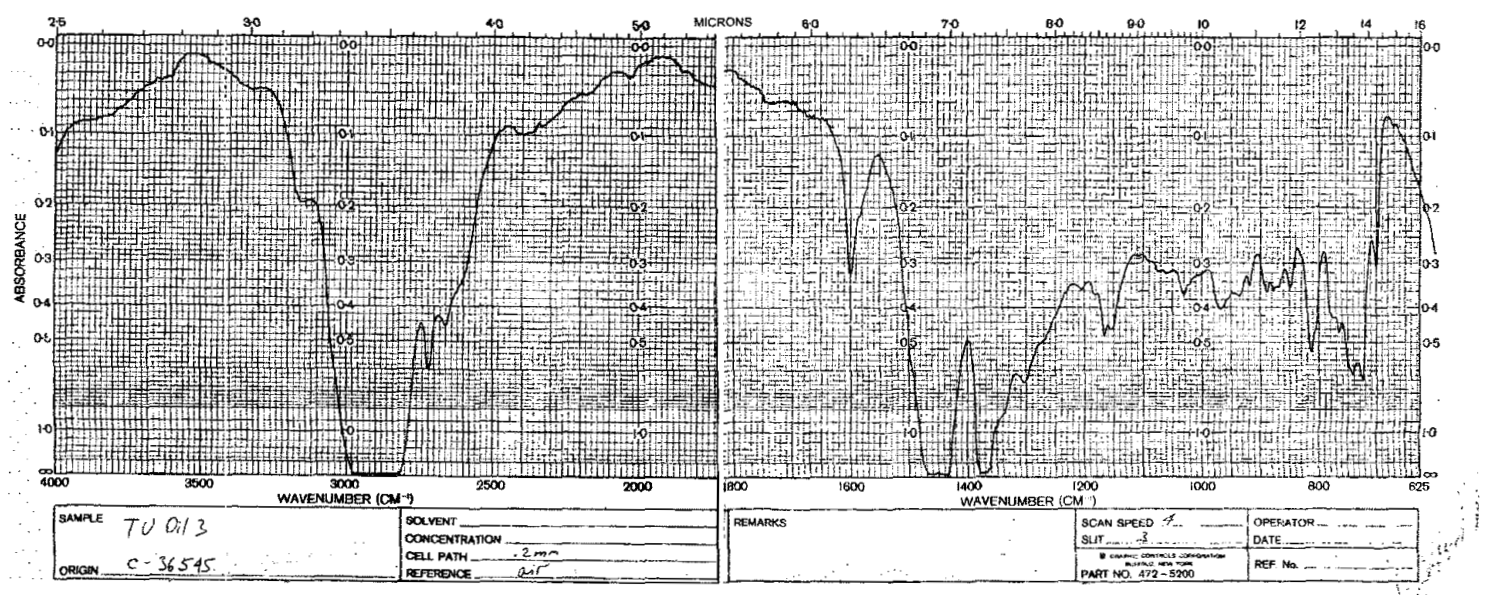

Figure 7. IR scan for the tested TU oil with $0.2 \mathrm{~mm}$ cell path and air as reference beam. The absorbance difference in signature band around 700 to $1200 \mathrm{~cm}^{-1}$ shows that the Ramapo and TU oils are different products.

cause a false reading.

Griffin et al. at Doble Enģineering Company [9] extensively studied moisture solubility in mineral oils. From their measurements of ten in-service aged oils and two oils with accelerated oxidation in the laboratory, they concluded that: "oils which are in serviceable condition show little change in their water solubility characteristics. Only when the oil is severely aged or contaminated would the solubility be expected to increase significantly". Our results agree with the Doble conclusion.

\section{CONCLUSION}

$\mathrm{M}$ OISTURE solubility is one important parameter in oil moisture measurements. This paper aims to propose a new method to mea- sure moisture solubility; and examine the general perception that the transformer oils under different conditions have different solubility.

A measurement technique exploiting the linearity between the relative humidity of the oil and the moisture content of the oil to indirectly measure the solubility is proposed. It avoids the difficulty of achieving full saturation of the test sample and associated errors. However, it can give the correct solubility only when the sensor response maintains linearity.

While moisture is an important parameter for the oil condition, our test results indicated that there were no significant differences in moisture solubility among differently aged oils. This agrees with Griffin's results [9] indicating that normal operation under service temperature is less likely to change the water solubility significantly. We believe that this work contributes to the present limited understanding of the aging vs. moisture solubility relationship. 


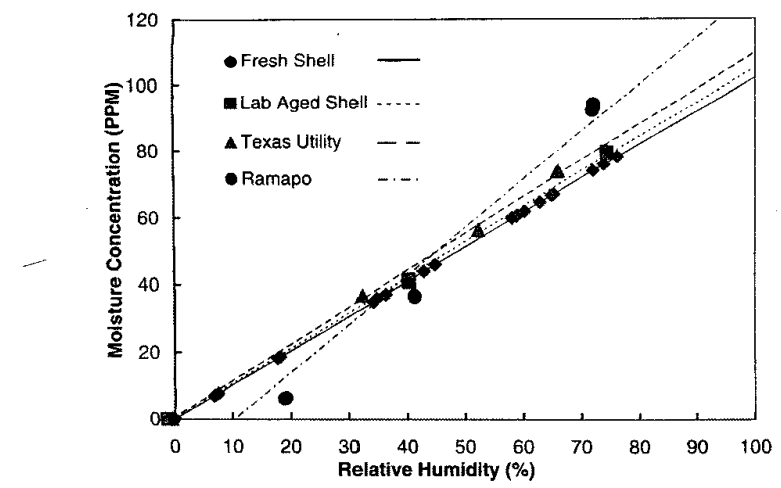

Figure 8. Measurements of moisture concentration vs. the relative humidity for differently conditioned oils at $35^{\circ} \mathrm{C}$.

\section{ACKNOWLEDGMENT}

The authors would like to acknowledge gratefully the financial support of the Electric Power Research Institute, under grant WO 8619-01, managed by Mr. S. Lindgren, the National Science Foundation under grant No. ECS-9523128, the Demonstration of Energy-Efficiency Developments Scholarships for Y. Du and A. Mamishev from American Public Power Association, sponsored by Belmont Utility managed by Mr. T. McCarthy, and a Link Foundation Fellowship for A. Mamishev. The authors would like to thank the reviewers for their excellent comments, Mr. Wayne Ryan of MIT for assistance with experiments, Mr. Paul Griffin of Doble Engineering Company and Mr. Larry Morrison of Equilon Enterprises L.L.C. for valuable discussions and technical support.

\section{REFERENCES}

[1] Transformers use edible seed-oil-based fluid, IEEE Power Engineering Review, Vol. 19, p. 34, Feb. 1999.

[2] T. O. Rouse, "Mineral insulating oil in transformers", Electrical Insulation Magazine, Vol. 14, no. 3, pp. 6-16, 1998

J. Fabre and A. Pichon, "Deterioration processes and products of paper and oil. Application to transformers", Proceedings of the International Conference on Large High Voltage Electric Systems (CIGRE), (Paris, France), Paper No. 137, June 15-25, 1960 :
[3] P. J. Griffin and J. D. Christie, "Effects of water and benzotriazole on electrostatic charge generation in mineral oil/cellulose systems", EPRI Proceedings: Static Electrification in Power Transformers, Project 1499-99, June 1993

[4] Relative Humidity, Britannica Online, 1994-1997 Encyclopedia Britannica, Inc., URL: http://www.britannica.com/.

[5] Standard test methods for water in insulating liquids, Karl Fischer reaction method (ASTM D 1533-86). Annual Book of ASTM Standards, 10.03, 1987.

[6] B. Fallou, Summary of work done at l.c.i.e. on the paper-oil complex, Internal Report of Laboratoire Centre des Industries Electriques, France.

[7] Standard test methods for estimation of solubility of water in hydrocarbon and aliphatic ester lubricants, ASTM D4056-92(1997). Annual Book of ASTM Standards, 05.02, 1998.

[8] P. J. Griffin, C. M. Bruce, and J. D. Christie, 'Comparison of water equilibrium in silicone and mineral oil transformers", Minutes of the Fifty-Fifth Annual International Conference of Doble Clients, Paper No.10-9, 1988.

[9] E. Nowak, "Moisture measurement with capacitive polymer humidity sensors", Sensors, pp. 86-91, Oct. 1996.

[10] M. Ardis and R. B. Kenney, "Capacitive-type moisture sensors", Sensors, pp.42-47, Feb. 1996

[11] P. A. von Guggenberg and J. R. Melcher, "An immersible relative saturation moisture sensor with application to transformer oil", in Proceedings of The 3rd International Conference on Properties and Applications of Dielectric Materials, Vol. 2, (Tokyo, Japan), pp. 1258-1261, July 8-12, 1991.

[12] Harley Moisture Sensor, Model CT-880-BN-H-(0-100\%)-X, J. W. Harley Inc., Monitoring Products Group.

[13] Shell Oil Company, Shell Diala Oils, Shell Lubricants Technical Bulletin SOC: 39-95.

[14] Test report by Doble Engineering Company, Report No. 30187, Nov. 11, 1996.

[15] Standard test methods for ASTM color of petroleum products, ASTM color scale (ASTMD 1500-82). Annual Book of ASTM Standards, 10.03, 1987.

[16] R. T. Conley, Infrared Spectroscopy. 2nd Edition, Allyn and Bacon, Inc., Boston, 1972

[17] G. D. Golovan, T.B. Zhilyaev, A.I. Panchenko, and V.S. Kriven'kaya, "Water solubility in transformer oils with various hydrocarbon compositions", Chemistry and Technology of Fuels and Oils, Vol. 20, pp. 387-391, July 1984.

[18] T. V. Oommen, "Moisture equilibrium in paper-oil insulation systems", Proceedings of the 16th Electrical/Electronics Insulation Conference, (Chicago, IL), pp. 162-166, Oct.3-6, 1983

[19] Test report by Doble Engineering Company, Report No. C36545, Mar. 8, 1999.

\footnotetext{
${ }^{1}$ Now with Exponent Failure Analysis Associates, Menlo Park, CA.

${ }^{2}$ Now with University of Washington Seattle, WA.

${ }^{3}$ Chung Cheong College, Department of Industrial Safety Engineering, Cheongwon-Kun, Churg-buk, Korea

Manuscript was received on 12 April 2000, in final form 3 August 2001.
} 